\title{
Ants Can Acquire Multiple Symbolisms
}

\author{
Marie-Claire Cammaerts ${ }^{1} \&$ Roger Cammaerts $^{2}$ \\ 1 Independent researcher, retired from the Biology of Organisms Department, University of Brussels, Belgium. \\ 2 Independent researcher, retired from the Natural and Agricultural Environmental Studies Department (DEMNA) \\ of the Walloon Region, Belgium. \\ Correspondence: Marie-Claire Cammaerts, independent researcher, 27, Square du Castel Fleuri, 1170 Bruxelles, \\ Belgium, tel: 32267349 69; Email address: mccammaerts@gmail.com
}

Received: July 4, 2020

doi:10.5539/ijb.v12n3p18
Accepted: August 13, 2020

Online Published: August 31, 2020

URL: doi: 10.5539/ijb.v12n3p18

\begin{abstract}
The workers of the ant Myrmica sabuleti were previously shown to be able to associate a given amount to its corresponding symbol, one symbol at a time. It was here examined if they can simultaneously learn to associate the amount 1 with a corresponding symbol, the amount 2 with another symbol, the amount 3 with a third symbol, and the amount 4 with a fourth symbol, the cue to avoid being the amount 5 . Thanks to operant conditioning during 156 hours and twelve successive testing experiments, it was shown that the ants can effectively memorize, in the course of a same time period, the association between the amounts 1,2,3, and 4 and their respective symbols. A distance effect was observed for the learning of the amounts 1 to 4 versus 5, but not for the learning of their four corresponding symbols.
\end{abstract}

Keywords: distance effect, numerosity, Myrmica sabuleti, operant conditioning, training

\section{Introduction}

Humans largely use symbolism in numerous practical and scientific fields such as travelling, writing, doing music, doing mathematics, physics, chemistry, etc. Humans have a tendency to learn some kind of symbolism to their pet animals, as well as even to their bees, for more easily taking care of them. This learning of symbolism to animals is easy and rather quick, animals soon reacting to the symbols humans want they memorize. In fact, in the wild, animals by themselves use several kinds of symbols which provide them some facility for making their tasks, e.g. defending a territory, memorizing the way to food sites and to their nest, controlling their relationships with congeners (Pearce, 2008). This is particularly developed in social animals and among them in bees and ants (Passera \& Aron, 2005). Wanting to compare the ants' numerosity abilities with those of other animal species, we recently examined these abilities in an ant, Myrmica sabuleti Meinert, 1861 (Cammaerts \& Cammaerts, 2019 a, b, c; 2020 a, b; Cammaerts, R. \& Cammaerts, M.C., 2020). At first glance, these abilities resemble those of vertebrates including humans (e.g. natively having a left to right oriented number line, acquiring the notion of zero through experiences), but the ants did not reach the abstraction level. Nevertheless, we thought that ants could be able to acquire a numerosity symbolism. This is why we undertook a series of works on ants' numerical symbolism. We have previously shown that the workers of the ant $M$. sabuleti can learn, through conditioning, to associate a number of elements $(1,2,3$ or 4$)$ to a corresponding symbol (Cammaerts \& Cammaerts, 2020c). During this study, the ants were trained to only one number and its corresponding symbol; they thus acquired single numerical symbolism. Here, we examined if ants can succeed in associating at the same time several numerosities with their corresponding symbols.

Multiple symbolisms acquisition is of course largely detained by humans, and could be obtained in several animals' species. Concerning invertebrates, up to now only honeybees have been shown to detain this ability, having succeeded in learning associating at the same time two symbols with their corresponding numerosity. They were however not able to reverse their learning, as bees having learned to associate a quantity with a symbol were unable to associate this symbol to its numerosity and vice versa (Howard, Avarguès-Weber, Garcia, Greentree, \& Dyer, 2019a). Some vertebrates have been shown to be able to acquire multiple symbolisms at a higher level. Pigeons could associate four visual symbols with 1 to 4 elements (Xia, Siemann \& Delius, 2000). A grey parrot (Psittacus erithacus) could associate 6 different vocal and visual symbols with 1 to 6 elements (Pepperberg, 2006a, b). As for the chimpanzees (Pan troglodytes), they succeeded in associating up to 7 or 9 Arabic numerals with their 
corresponding numbers of elements (Murofushi, 1997; Matsuzawa, 1985; Beran, 2004), including at the same time the symbol 0 for the element meaning "nothing" (Biro \& Matsuzawa, 2001). Rhesus monkeys (Macaca mulatta) could be learned to associate the Arabic numerals 0 to 9 with their corresponding numbers of food items (Washburn \& Rumbauch, 1991). Squirrel monkeys (Saimiri sciureus) and capuchin monkeys (Cebus apella) were shown to also detain this numerosity ability (Olthof, Iden, \& Roberts, 1997; Beran et al., 2008).

In the present work, we tried to learn ants to associate four particular symbols with their corresponding numbers of elements ( 1 to 4 black circles) versus a quantity of elements to avoid (5 black circles). We worked on two large colonies of the ant M. sabuleti, using operant conditioning and a different reward for each numerosity (1 to 4$)$ and its corresponding symbol to learn, and no reward for the numerosity 5 .

\section{Material and Methods}

\subsection{Ants' Collection and Maintenance}

The experiments were performed on two colonies of $M$. sabuleti collected in an abandoned quarry at Olloy/Viroin (Ardenne, Belgium) during September 2019. They nested in grass and under stones and contained about 500-700 workers, a queen and brood. Each colony was maintained in the laboratory in two or three glass tubes half filled with water, a cotton plug separating the ants from the water (Figure 3 ). The nest tubes of each colony were placed in a tray $(34 \mathrm{~cm} \times 23 \mathrm{~cm} \times 4 \mathrm{~cm})$ serving as a foraging area, the borders of which having been covered with talc to prevent ants from escaping. In this area, pieces of Tenebrio molitor larvae (Linnaeus, 1758) were deposited three times per week on a glass piece, and a 30\% aqueous sugar solution was provided ad libitum in a cotton plugged tube. The lighting equaled about 330 lux while working on ants, the ambient temperature was permanently $c a 20^{\circ} \mathrm{C}$, the humidity $c a 80 \%$, and the electromagnetism $2 \mu \mathrm{Wm}^{2}$, all these conditions being suitable for the species.

\subsection{Cues Presented to the Ants}

The cues presented to the ants were 1, 2, 3 and 4 black circles (diameter $=3 \mathrm{~mm}$ ) and their corresponding distinct

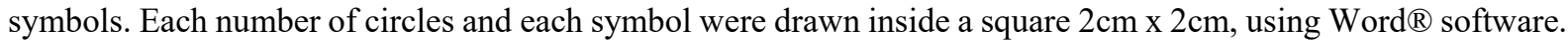
All these squares with a number of circles or a symbol inside of them were printed and cut, then tied on the front face of a stand. Each stand was made of strong white paper (Steinbach $\left.{ }^{\circledR}\right)$, had a vertical part $(2 \mathrm{~cm} \mathrm{x} 2 \mathrm{~cm}$ ) and was maintained vertically thanks to a duly folded horizontal part $[2 \times(1 \mathrm{~cm} \times 0.5 \mathrm{~cm})]$ (Figure 1).

The ants were simultaneously trained to the four numbers of circles (1 to 4$)$ and to their four corresponding symbols. Each stand bearing a given number of circles and the stand with the corresponding symbol were located aside a reward. The numerosity 1 was located near the ants' meat food, the numerosity 2 near the ants' sugar water tube, the numerosity 3 near pieces of thyme, and the numerosity 4 near the nest entrance (Figure 2). The number and its symbol were inversely set for colony A and B (Figure 3). Far from these four locations, behind the ants' nest tubes, two stands bearing 5 black circles were set with no associated reward: they were the kind of cue to not memorize, to avoid (Figures 2,3). The ants were tested over their continuous training, in the course of twelve successive daily testing experiments, in front of two stands, the one bearing a given number of circles or a symbol, the other bearing 5 black circles. Details on training and testing are given just below. 

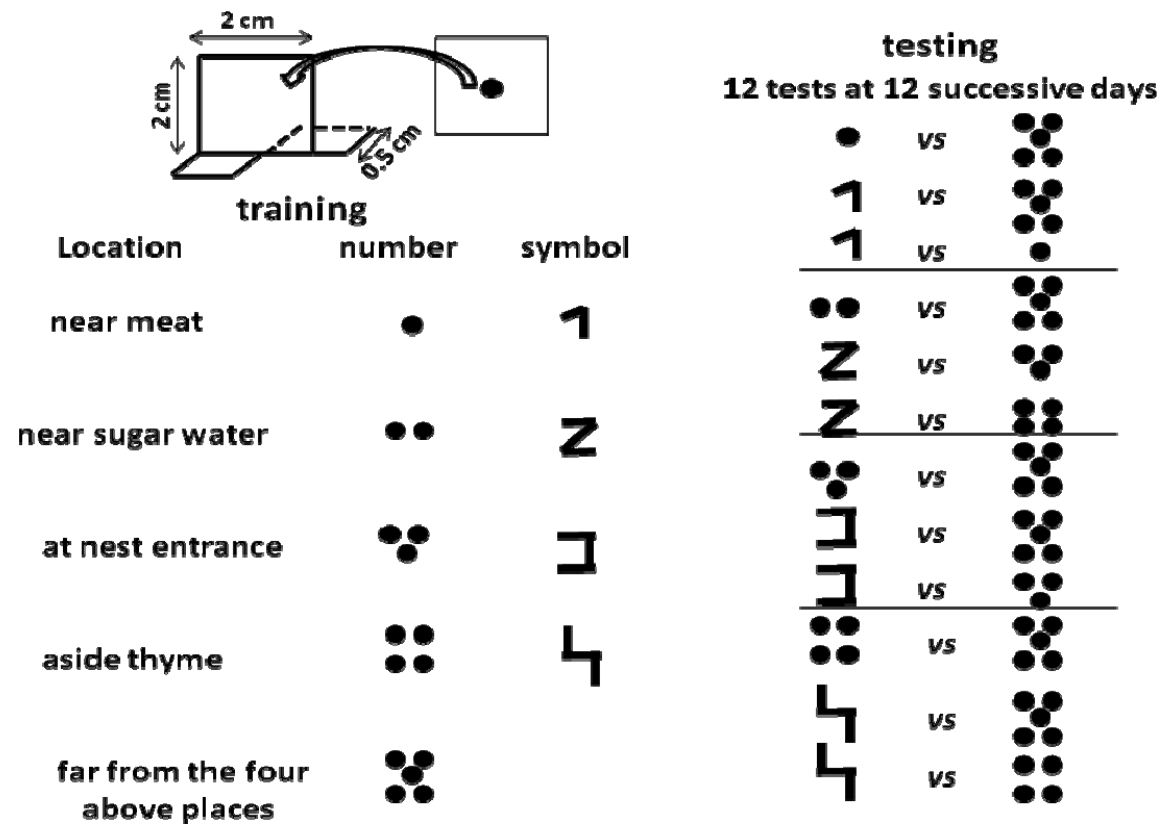

Figure 1. Numbers of elements and their symbols used to learn their associations to the ants

The ants were continuously trained in their foraging area to four numbers of elements and their corresponding symbols. They were successively tested outside their foraging area in front of these cues to see if they could acquire the multiple numerical symbolisms presented during training. See details in the text, a schema in Figure 2 and illustrations in Figures 3 and 4.

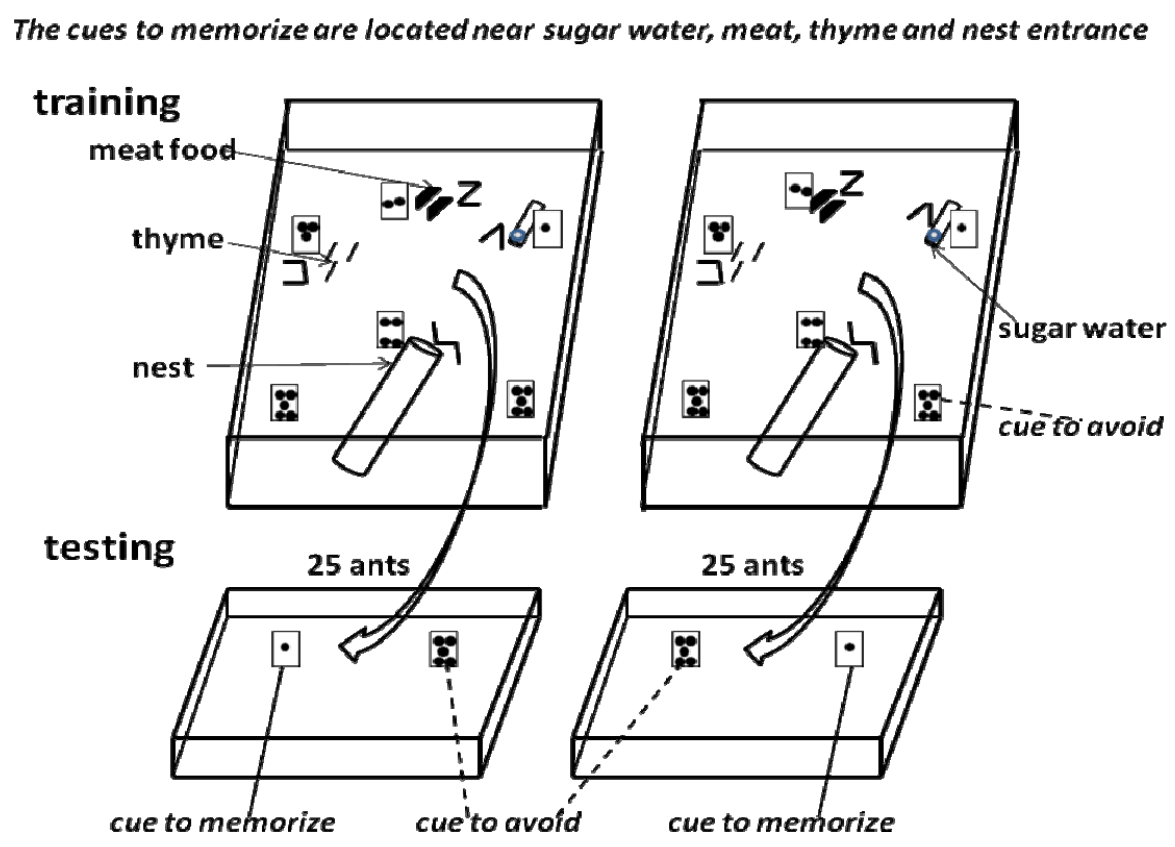

Figure 2. Experimental design used for tempting learning to ants the association of four symbols to their respective number of elements

The ants of two colonies were trained at the same time to four numbers of elements and their symbols in their foraging area (upper part). They were tested in the course of twelve successive experiments, in a separate tray, each time in front of two cues (see details in Figure 1) for checking if they learned the association of each quantity to its corresponding symbol. Details are given in the text and illustrations are shown in Figures 3 and 4. 


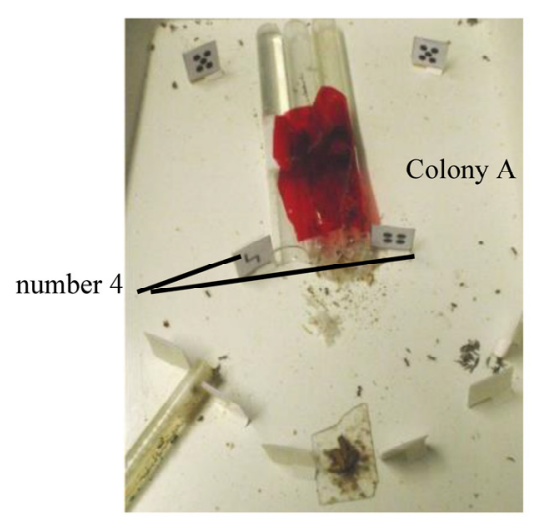

front view
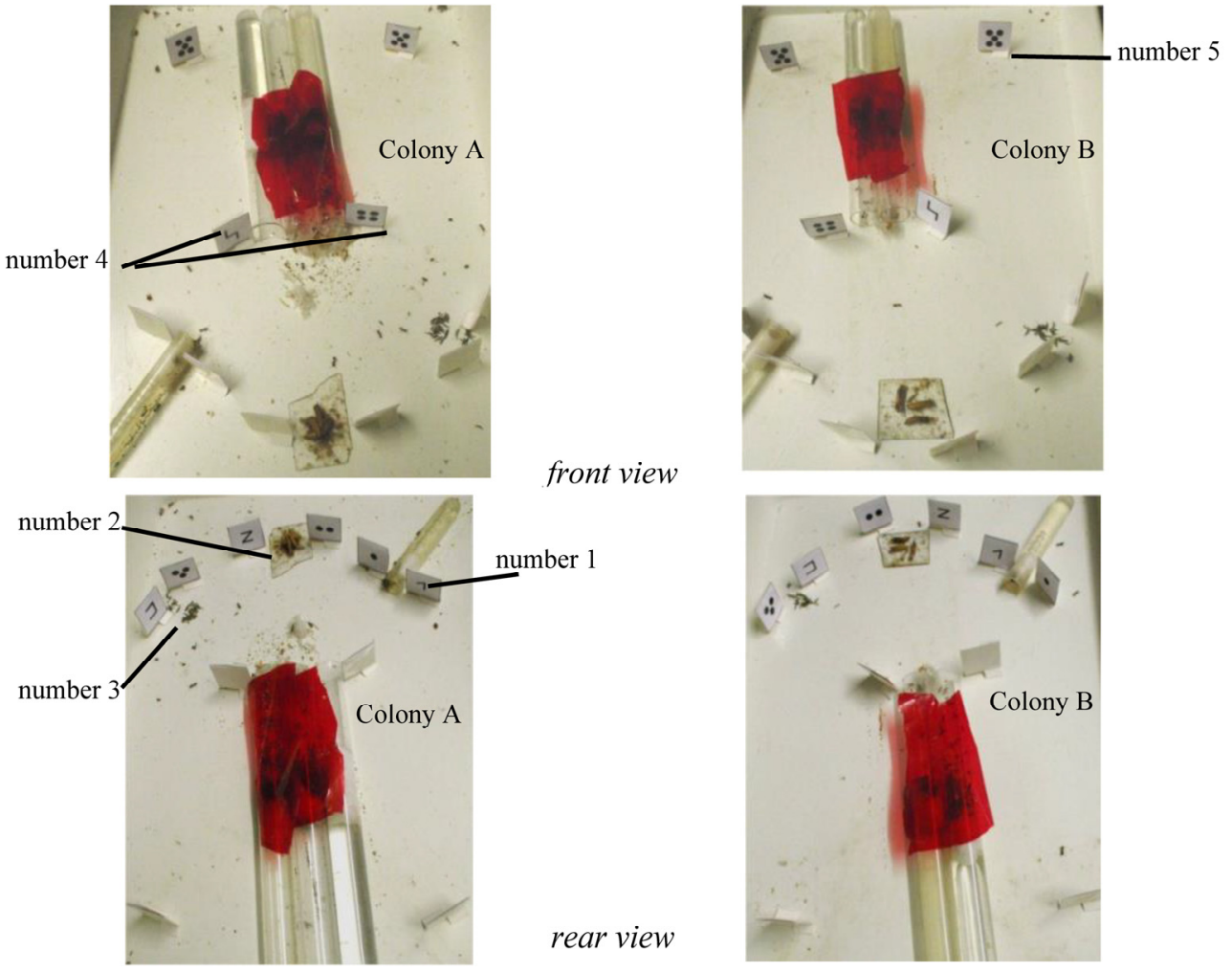

Figure 3. Experimental design used to learn four symbolisms to ants, a symbol for 1 to 4 numbers of elements.

This figure illustrates what is schematically presented in Figures 1 and 2.

\subsection{Ants' Training}

All along their training, the ants of each colony were counted four times, each day at about the same time o'clock, for checking if they could effectively see the 20 presented cues. The total number of counts was thus 12 (days) $\mathrm{x} 2$ (colonies) $\mathrm{x} 4$ (times) $=96$. The mean and the extreme values of these counts were established and are given in the text only.

\subsection{Ants' Testing}

Twelve tests were successively performed with a 12-hour interval between them, beginning after 24 and ending after 156 training hours. The ants were tested in a separate tray $(21 \mathrm{~cm} \mathrm{x} 15 \mathrm{~cm} \times 7 \mathrm{~cm})$, the borders of which having been slightly covered with talc to prevent escaping, and in which two cues had been set at about $8 \mathrm{~cm}$ from one another (Figure 2). These two cues are schematized in Figure 1 and can be seen in Figure 4. The first set of three experiments concerned the numerosity 1 ; the second set, the numerosity 2 ; the next set, the numerosity 3 ; the last one, the numerosity 4 . For each set, the first of the three experiments enabled to compare the ants' response to a given number of circles to which they were conditioned with their response to the 5 circles to which they were not conditioned, the second experiment compared the ants' response to the symbol corresponding to this given number of circles with their response to the 5 circles, and the last experiment compared the ants' response to the concerned number of elements with their response to its corresponding symbol. To make a test, 25 foragers (a number allowing an easy counting of the ants according to the dimensions of the testing tray) of a colony were transferred at once from their foraging area into the tray devoted to testing, in the middle space between the two stands bearing the cues. For one colony, the tests were made with the symbol or the correct number of elements on the left; for the other colony, the tests were made with these cues on the right. The tested ants moved freely in their new space, and approached each of the two cues. The numbers of those approaching each cue at a distance less than $2 \mathrm{~cm}$ were punctually counted 20 times (at each 30 seconds) over 10 experimental minutes. These counts enabled calculating the proportion of responses given to each of the two cues presented to 25 ants of each colony. Summing chronologically by four the twenty numbers of ants obtained for each cue enabled to get five numbers, and thus for each couple of cues presented to ants, five pairs of numbers. The statistical comparison between the numbers of ants sighted in the vicinity of each cue of the two presented ones was made using three kinds of analysis (Table 1). Summing the chronologically corresponding numbers of the two colonies enabled to compare a total of 5 pairs of 
values (Table 1, column 3), while not adding them enabled to make 10 pairwise comparisons (Table 1 column 4), in both case using the non-parametric matched-pairs signed-ranks test of Wilcoxon. When the twenty counts obtained for each cue and each colony were not grouped, 40 pairwise comparisons could be made by using the non-parametric sign test (Table 1, column 5). The critical P values for small samples were read in Siegel and Castellan's (1988) Tables H (Wilcoxon test) or D (sign test). A one-tailed test was used when the comparisons involved a cue with 5 circles since conditioning predicts that this cue should be less responded to. A two-tailed test was used when the comparison of the ants' responses involved 1 to 4 circles against their corresponding symbols, the ants having been conditioned to each of these kinds of cues. The statistical results are given in Table 1. After each test, the ants were transferred again into their foraging area, near their nest entrance.

Table 1. Ants' response to two cues presented during twelve successive testing experiments, the ants being continuously conditioned to all the cues

\begin{tabular}{|c|c|c|c|c|c|c|c|c|c|}
\hline \multirow{3}{*}{ Presented cues } & \multirow{3}{*}{$\begin{array}{l}\mathrm{n}^{\circ} \text { of ants of colonies A and B near one } \\
\text { vs the other cue }\end{array}$} & \multicolumn{8}{|c|}{ Pairwise statistical comparisons } \\
\hline & & \multicolumn{3}{|c|}{$\begin{array}{l}\text { Wilcoxon test, } \\
\text { each time } 5 \\
\text { pairs of four } \\
\text { summed values } \\
\text { (col. A + B })\end{array}$} & \multicolumn{3}{|c|}{$\begin{array}{l}\text { Wilcoxon test, } \\
\text { each time } 10 \\
\text { pairs of four } \\
\text { summed values } \\
\text { (col. A, then B) }\end{array}$} & \multicolumn{2}{|c|}{$\begin{array}{c}\text { Sign test, } \\
\text { each time } \\
40 \text { pairs of } \\
\text { single values }\end{array}$} \\
\hline & & $\mathrm{N}$ & $\mathrm{T}$ & $\mathrm{P}$ & $\mathrm{N}$ & $\mathrm{T}$ & $\mathrm{P}$ & $\mathrm{N}$ & $\mathrm{P}$ \\
\hline 1 circle $v s 5$ circles & 25 and $45(78.5 \%)$ vs 7 and $12(21.5 \%)$ & 5 & 15 & 0.031 & 10 & 55 & 0.010 & 33 & $<0.001$ \\
\hline symbol 1 vs 5 circles & 18 and $34(73.2 \%)$ vs 7 and $12(26.8 \%)$ & 5 & 15 & 0.031 & 9 & 45 & 0.020 & 29 & $<0.001$ \\
\hline 1 circle $v s$ symbol 1 & 27 and $23(52.6 \%)$ vs 30 and 15 (47.4\%) & 4 & 8.5 & 0.314 & 9 & 29.5 & 0.462 & 17 & 0.332 \\
\hline 2 circles $v s 5$ circles & 30 and $29(71.9 \%)$ vs 10 and $13(28.1 \%)$ & 5 & 15 & 0.031 & 9 & 45 & 0.020 & 32 & $<0.001$ \\
\hline symbol 2 vs 5 circles & 26 and $28(76.1 \%)$ vs 6 and 11 (23.9\%) & 5 & 15 & 0.031 & 10 & 55 & 0.010 & 31 & $<0.001$ \\
\hline 2 circles $v s$ symbol 2 & 39 and $37(53.9 \%)$ vs 31 and $34(46.1 \%)$ & 4 & 10 & 0.126 & 7 & 26 & 0.046 & 14 & 0.012 \\
\hline 3 circles $v s 5$ circles & 43 and $38(69.8 \%)$ vs 16 and 19 (30.1\%) & 5 & 15 & 0.031 & 10 & 55 & 0.010 & 33 & $<0.001$ \\
\hline symbol 3 vs 5 circles & 35 and $32(78.8 \%)$ vs 9 and $9(21.2 \%)$ & 5 & 15 & 0.031 & 10 & 55 & 0.010 & 37 & $<0.001$ \\
\hline 3 circles $v s$ symbol 3 & 24 and $25(47.1 \%)$ vs 27 and 28 (52.9\%) & 3 & 6 & 0.250 & 7 & 6.5 & $>0.50$ & 12 & 0.092 \\
\hline 4 circles $v s 5$ circles & 39 and $31(68.0 \%)$ vs 14 and $19(32.0 \%)$ & 5 & 15 & 0.031 & 9 & 44 & 0.039 & 33 & $<0.001$ \\
\hline symbol 4 vs 5 circles & 24 and $30(74.0 \%)$ vs 6 and $13(26.0 \%)$ & 5 & 15 & 0.031 & 10 & 55 & 0.010 & 33 & $<0.001$ \\
\hline 4 circles $v s$ symbol 4 & 33 and $23(47.5 \%)$ vs 36 and 26 (52.5\%) & 4 & 10 & 0.126 & 8 & 9.5 & $>0.50$ & 16 & 0.210 \\
\hline
\end{tabular}

The ants of two colonies were continuously conditioned to the numbers 1 to 4 and their corresponding symbols. They were tested in front of these cues presented by pairs, over 156 hours, for examining if they could acquire the multiple numerosity symbolisms they sighted during training. The $\mathrm{P}$ values correspond to a one-tailed test when the comparison involves a cue with 5 circles and to a two-tailed test for a comparison between the ants' response to a symbol and its associated number of 1 to 4 elements. See Materials \& Methods for explanations. $N=$ number of pairs whose differences show a sign. $\mathrm{T}=$ the larger sum of like-signed ranks. Figures 1, 2, 3 and 4 show the experimental protocol and details can be found in the text.

\section{Results}

\subsection{Presentation of the Results}

Numerical and statistical results are given in Table 1 and photos of the experiments are shown in Figures 3 (training) and 4 (testing). Results are commented here below, considering successively the numerosities 1, 2, 3 and 4 , and for each of them, successively, the ants' response to the numerosity represented by a number of 1 to 4 black circles $v s$ black circles, to the symbol corresponding to this numerosity $v s 5$ black circles, and finally to the numerosity $v s$ its corresponding symbol. 


\subsection{Results}

During their training, the ants of the two colonies were numerous enough all around the ten presented cues for seeing and memorizing them as well as their location. Indeed, they were meanly 11.2 ones (extremes: 8 and 17) in moving or staying motionless in the vicinity of the different cues.

Tested faced with a black circle and 5 ones, the ants went essentially to the 1 circle: 70 of their responses were for that cue while 19 were for the 5 circles, and this difference was significant. Confronted to the symbol for 1 circle and to 5 black circles, the ants went essentially to the symbol: 52 responses concerned that cue and 19 the 5 circles. The difference was also significant. Faced with 1 black circle and the symbol for 1, the ants went nearly equally to the two cues: they went 50 times to the black circle and 45 times to the symbol for 1 , the difference between these two scores being not significant. The ants have thus duly associated the symbol for 1 with 1 black circle, responding equally to them and distinguishing these two cues from 5 circles.

When tested in front of 2 and 5 black circles, the ants approached mostly the 2 circles: 59 approaches concerned that cue while 23 concerned the 5 circles. This difference was significant. Note that the obtained proportion of correct responses $(71.9 \%)$ was somewhat lower than that obtained for 1 black circle $(78.5 \%)$, what could be accounted for a distance effect such as the one previously pointed out in the same ant species (Cammaerts \& Cammaerts, 2020d). Faced with the symbol for 2 and 5 black circles, the tested ants went also more to the symbol (54 times) than to the 5 circles (17 times), the difference between the two scores being significant. Note that the ants somewhat better responded to the symbol 2 than to the amount 2 when they were compared against 5 circles, since for the symbol, no distance effect occurred. Confronted to the symbol for 2 and 2 black circles, the ants went nearly equally to these two cues: in total: they went 65 times to the symbol and 76 times to the 2 black circles. The difference between these two results was significant or not, according to the statistical comparison. However, whatever the kind of statistical comparison, 2 circles versus their symbol always led to a much higher $\mathrm{P}$ value than whichever comparison versus 5 circles. In the case of the sign test, the latter kind of comparison always provided a $\mathrm{P}$ value in the range of $10^{-6}$, a value simplified in Table 1. It could thus be concluded that the ants associated the symbol for 2 with the amount 2, though having moreover associated the symbol 1 with the amount 1 (above alinea).

Concerning the ants' association between a symbol for 3 and the amount 3, when tested faced with 3 black circles and 5 such circles, the ants responded essentially to the 3 circles: in total, 81 of their responses were for that cue while 35 were for the 5 circles, a significant difference. Faced with the symbol for 3 and 5 black circles, the ants went far more often to the symbol than to the 5 circles: 67 of their responses were for the symbol while 18 were for the 5 circles, a difference of course significant. In presence of 5 black circles, the ants responded better to the symbol $(78.8 \%)$ than to the 3 circles $(69.8 \%)$, because the symbol could be more easily distinguished from the 5 circles than 3 circles from 5 circles, and because the discrimination between 3 and 5 circles could be impacted by some proximity, a distance effect pointed out in Cammaerts and Cammaerts (2020d). In the presence of 3 black circles and the symbol for 3, the tested ants went nearly equally to these two cues: in total, the ants responded 55 times to the symbol and 49 times to the 3 black circles. There was no statistical difference between these preferences. The ants have thus associated the symbol for 3 with the amount 3 , having similarly responded to each of these two cues $(52.9 \%$ and $47.1 \%)$ and significantly distinguished each of these two cues from the 5 circles. Having also been able to associate the symbol for 1 with the amount 1 and the symbol for 2 with the amount 2, they could thus acquire three kinds of associations during a same time period.

Could the ants acquire, during the same training period, a fourth association? i.e. that between a symbol for 4 and the amount 4 ? Tested in front of 4 black circles and 5 black circles, the ants reacted mostly to the 4 black circles: 70 of their reactions concerned the 4 circles while 33 ones concerned the 5 circles. These two results statistically differed. The here obtained proportions somewhat differed from those obtained for 1, 2, and 3 black circles $v s 5$ black circles. This could again find an explanation in the frame of a distance effect. Confronted to the symbol for 4 and 5 black circles, the ants approached mostly the symbol: 54 approaches concerned the symbol while 19 concerned the 5 circles. Such a difference was significant, and was somewhat larger ( $74 \%$ vs $68 \%)$ than that observed for 4 vs 5 circles, perhaps because the distinction between a symbol and 5 circles was not affected by a distance effect. When tested in the presence of the symbol 4 and 4 black circles, the ants went often equally towards each of these two cues: in total, they went 62 times to the symbol and 56 times to the 4 black circles, the difference between these two scores being not significant. The ants have thus associated the symbol for 4 and the amount 4 . They had also associated, during the same time period, the symbol for 1, 2, and 3 with the amounts 1, 2, and 3 respectively. They could thus acquire multiple numerical symbolisms, at least until the number 4 . 

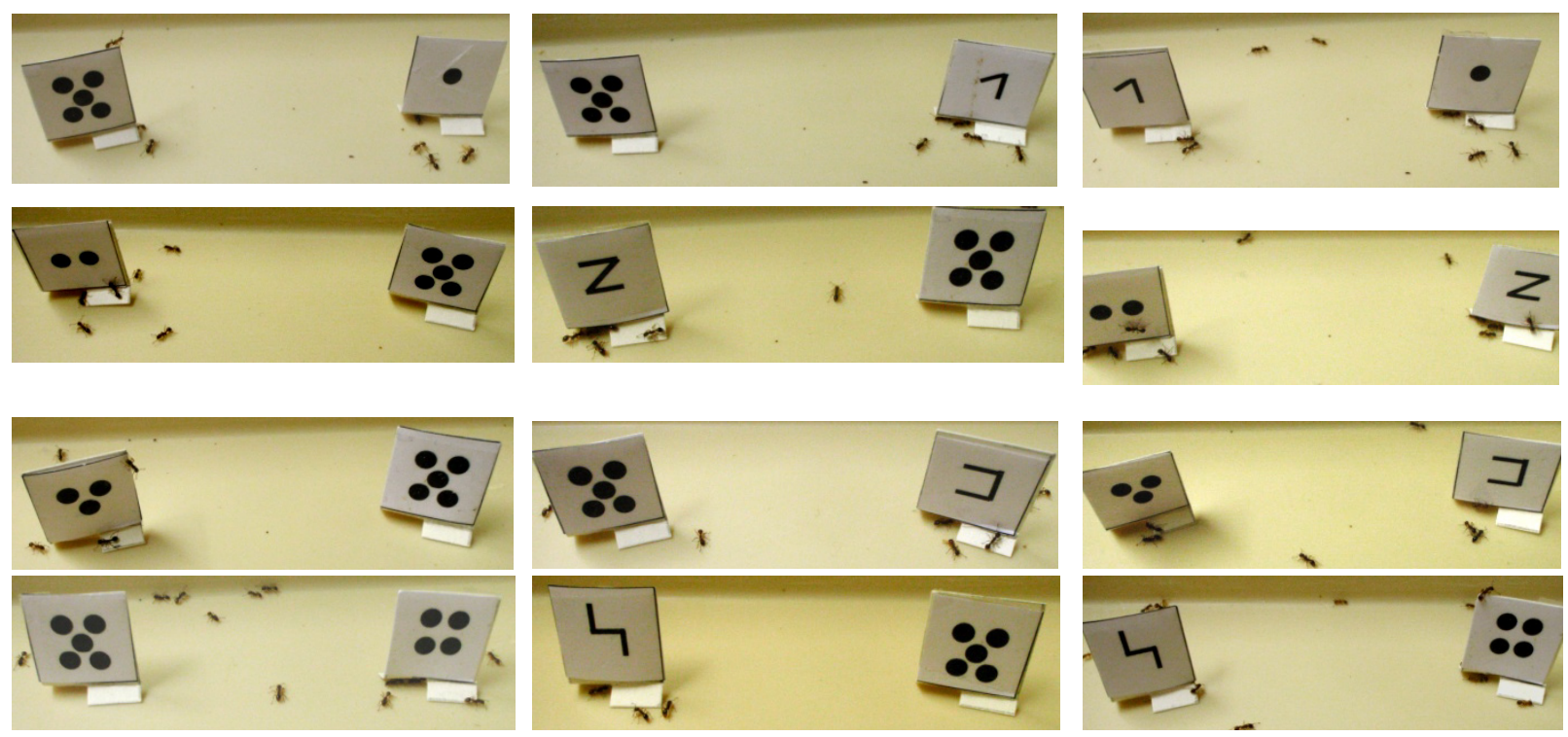

Figure 4. Some views of the tests performed on the ants' conditioning to numbers 1 to 4 and their corresponding symbol (see Figure 3).

Lines 1 to 4 : respectively, experiments relative to the numbers 1 to 4 and their corresponding symbol. Columns 1 to 3: respectively ants' response to a numerosity $v s 5$ circles, to the symbol associated with this numerosity $v s 5$ circles, and to the symbol vs its associated numerosity. Each time, the ants better responded to the numerosity or the symbol than to the 5 black circles, and similarly to the number of dots and to its corresponding symbol. They could thus acquire multiple numerical symbolisms, at least until the numerosity represented by 4 black circles.

\section{Discussion - Conclusion}

In order to know if ants can acquire multiple symbolisms as do humans and animals until now studied as for this topic, and to improve our knowledge on the ants' numerical abilities, we here experimentally showed that the workers of the ant $M$. sabuleti can learn at the same time to associate several given numbers of elements to their respective symbols. Indeed, the ants' choice between a symbol and its learned corresponding numerosity did not statistically differ (for symbols 1, 3 and 4) or at least this difference was less dissimilar (for symbol 2) than that of their responses towards an incorrect cue (5 circles). Moreover, the use of the sign test (Table 1) showed that the number $\mathrm{N}$ of non-null pairwise simple comparisons between the four symbols and their corresponding numerosities amounted to less than half of the 40 counting sessions. More ants had thus no preference between a stand bearing a symbol and the stand bearing its corresponding numerosity than ants having preferred a symbol or its corresponding number of elements to the number of circles to avoid. The ants could thus acquire multiple associations between an amount and its corresponding symbol, at least for one to four numerical elements.

Tested in the course of time as for their simultaneous learning of four such associations, the ants' proportions of correct responses were similarly significant for each of the four associations, as $73.2 \%, 76.1 \%, 78.8 \%$ and $74.0 \%$ of the ants chose the symbol for 1, 2, 3 and 4 instead of the cue to avoid ( 5 circles). When tested for single symbolism acquisition (Cammaerts \& Cammaerts, 2020c), similar proportions were obtained for the symbols 1 to 4: $74.6 \%, 65.7 \%, 70.1 \%$ and $74.7 \%$. The ants acquired thus at the same time four numerical symbolisms with the same accuracy as that with which they acquired a single numerical symbolism.

In addition, a distance effect was observed for the learning of the numerosities 1 to 4 since the proportions of correct responses to the numbers of elements 1 to 4 versus the number 5 decreased (from $78.5 \%$ to $71.9 \%, 69.8 \%$ and $68 \%$ respectively), an effect previously pointed out in the same ant species (Cammaerts \& Cammaerts, 2020d). The present experimental work also revealed that the nest entrance as well as pieces of thyme (what was not food) can valuably reward the used ant species. The nest entrance is an essential element for the ants. Thyme forms part of the natural environment of $M$. sabuleti and the transport of pieces of this plant at the nest entrance by the workers of this species has often been observed (personal observations).

Comparing our results with those obtained by other researchers on other animals allows presuming that the ants' multiple symbolisms acquisition is similar to that of the bees, and appears to be of a lesser complexity than that acquired by the vertebrates until now studied for this topic (birds and monkeys: see the introduction). In 
chimpanzees, the acquisition of multiple numerical symbolisms by immersion in human culture could even change and ameliorate their cognitive abilities (Boysen, 2006). However, there exists a large difference, a gap, between numerical symbolisms acquired by humans through education, and the symbolism learned through conditioning by animals, including the non-human primates. The numerical competence of humans passes from an iconic to an indexical and finally to a symbolic stage, but animals are constrained to an indexical level (Nieder, 2009).

Honey bees have been shown to be able to associate a symbol such as a given color with an addition or a subtraction (Howard, Avarguès-Weber, Garcia, Greentree, \& Dyer, 2019b). Performing additions by using learned numerical symbols still waits to be tried on ants. Such a future experimental work should allow, through using multiple symbolisms, to define which stage (iconic or indexical) of numerical competence is reached by the ants. This is intended both to better define the boundaries of the ants' cognitive skills and to show that the acquisition of multiple symbolisms can be useful to ants in their usual tasks such as foraging, scouting, food exchange and recruitment.

\section{Conflicts of interests}

The authors declare that there is no conflict of interests regarding the publication of this paper.

\section{References}

Beran, M.J. (2004). Long-term retention of the differential values of Arabic numerals by chimpanzees (Pan troglodytes). Animal Cognition, 7(2), 86-92. Doi: 10.1007/s10071-003-0191-x

Beran, M.J., Harris, E.H., Evans, T.A., Klein, E.D., Chan, B., Flemming, T.M., \& Washburn, D.A. (2008). Ordinal judgments of symbolic stimuli by capuchin monkeys (Cebus apella) and rhesus monkeys (Macaca mulatta): The effects of differential and nondifferential reward. Journal of Comparative Psychology, 122(1), 52-61.doi:10.1037/0735-7036.122.1.52

Biro, D. \& Matsuzawa, T. (2001). Use of numerical symbols by the chimpanzee (Pan troglodytes): Cardinals, ordinals, and the introduction of zero. Animal Cognition, 4(3-4), 193-199. doi:10.1007/s100710100086

Boysen, S. T. (2006). The impact of symbolic representations on chimpanzee cognition. In S. Hurley \& M. Nudds (Eds.), Rational animals? (p. 489-511). Oxford University Press. https://doi.org/10.1093/acprof:oso/9780198528272.003.0022

Cammaerts, M.-C., \& Cammaerts, R. (2019a). Ants are at the first stage of the notion of zero. International Journal of Biology, 11 (1): 54-65 https://doi.org/10.5539/ijb.v11n1p54

Cammaerts, M.-C., \& Cammaerts, R. (2019b). Ants' capability of adding numbers of identical elements. International Journal of Biology, 11 (3): 25-36. https://doi.org/10.5539/ijb.v11n3p25

Cammaerts, M.-C., \& Cammaerts, R. (2019c). Left to right oriented number scaling in an ant. International Journal of Biology, 11 (4): 67-79. https://doi.org/10.5539/ijb.v11n4p67

Cammaerts, M.-C., \& Cammaerts, R. (2020a). Young ants already possess a number line. International Journal of Biology, 12 (2): 1-12. doi:10.5539/ijb.v12n2p1

Cammaerts, M.-C., \& Cammaerts, R. (2020b). Ants acquire the notion of zero through experiences. International Journal of Biology, 12 (2): 13-25. https://doi.org/10.5539/ijb.v12n2p13

Cammaerts, M.-C., \& Cammaerts, R. (2020c). Ants can associate a symbol with a number of elements through conditioning. International Journal of Biology, 12 (3): 1-13. doi:10.5539/ijb.v12n3p1

Cammaerts, M.-C., \& Cammaerts, R. (2020d). Non-numerical distance and size effects in an ant. Journal of Biology and Life Sciences, 11 (2), 13-35. https://doi.org/10.5296/jbls.v11i1.16895

Cammaerts, R., \& Cammaerts, M.-C. (2020). Ants' mental positioning of amounts on a number line. International Journal of Biology, 12 (1): 30-45. https://doi.org/10.5539/ijb.v12n1p30

Howard, S.R., Avarguès-Weber, A., Garcia, J.E., Greentree, A.D. \& Dyer, A.G. (2019a). Numerical cognition in honeybees enables addition and subtraction. Cognitive Neuroscience, 5: eaav0961. http://doi: 10.1126/sciadv.aav0961

Howard, S.R., Avarguès-Weber, A., Garcia, J.E., Greentree, A.D. \& Dyer, A.G. (2019b). Symbolic representation of numerosity by honeybees (Apis mellifera): matching characters to small quantities. Proceedings of the Royal Society B, 286, 20190238. http://dx.doi.org/10.1098/rspb.2019.0238

Matsuzawa, T. (1985). Use of numbers by a chimpanzee. Nature, 315(2): 57-59. Doi: 10.1038/315057a0 
Murofushi, K. (1997). Numerical matching behavior by a chimpanzee (Pan troglodytes): Subitizing and analogue magnitude estimation. Japanese Psychological Research, 39(32), 140-153. Doi: 10.1111/1468-5884.00050

Nieder, A. (2009). Prefrontal cortex and the evolution of symbolic reference. Current Opinion in Neurobiology, 19 (1), 99-108. https://doi.org/10.1016/j.conb.2009.04.008

Olthof, A., Iden, C.M., \& Roberts, W.A. (1997). Judgments of ordinality and summation of number symbols by squirrel monkeys (Saimiri sciureus). Animal Behavior Processes, 23(3), 325-339. Doi: 10.1037/0097-7403.23.3325

Pearce, J.M. (2008). Animal Learning and Cognition. USA, Canada, Psychology Press. www.psypress.com. psycnet.apa.org $>2008-01980-000$

Pepperberg, I.M. (2006a). Grey parrot numerical competence: a review. Animal Cognition, 9, 377-391. Doi: 10.1007/s10071-006-0034-7

Pepperberg, I.M. (2006b). Ordinality and inferential abilities of a grey parrot (Psittacus erithacus). Journal of Comparative Psychology, 120(3), 205-216.Doi: 10.1037/0735-7036.120.3.205

Siegel, S., \& Castellan, N.J. (1988). Nonparametric statistics for the behavioural sciences. Singapore, McGraw-Hill Book Company. https://www.amazon.com/Sidney-Siegel...Statistics.../B008WDIR6

Washburn, D.A., \& Rumbauch, D.M. (1991). Ordinal judgments of numerical symbols by macaques (Macaca mulatta). Psychological Science, 2(3), 190-193. https://doi.org/10.1111/j.1467-9280.1991.tb00130.x

Xia, L., Siemann, M., \& Delius J. D. (2000). Matching of numerical symbols with number of responses by pigeons. Animal Cognition. 3, 35-43. doi:10.1007/s100710050048

\section{Copyrights}

Copyright for this article is retained by the author(s), with first publication rights granted to the journal.

This is an open-access article distributed under the terms and conditions of the Creative Commons Attribution license (http://creativecommons.org/licenses/by/4.0/). 